\title{
1 Defensive structures influence fighting outcomes
}

3 Zachary Emberts ${ }^{1}$ and John J. Wiens ${ }^{1}$

4

$5{ }^{1}$ Department of Ecology and Evolutionary Biology, University of Arizona, Tucson, Arizona, 6 85721-0088, USA

8 Corresponding Author

9 Zachary Emberts

$10{ }^{1}$ Department of Ecology and Evolutionary Biology, University of Arizona, Tucson, Arizona

11 85721-0088, USA

12 E-mail: emberts@email.arizona.edu

13 


\section{ABSTRACT}

15 1. In many animal species, individuals engage in fights with conspecifics over access to limited resources (e.g. mates, food, or shelter). Most theory about these intraspecific fights assumes that damage has an important role in determining the contest winner.

2. Examples of such damage-reducing structures include the dermal shields of goats, the dorsal osteoderms of crocodiles, and the armored telsons of mantis shrimps. Although numerous studies have identified these defensive structures, no study has investigated whether they influence the outcomes of intraspecific fights.

3. Here, we investigated whether inhibiting damage by enhancing an individual's armor influenced fighting behavior and success in the giant mesquite bug, Thasus neocalifornicus (Insecta: Hemiptera: Coreidae).

4. We found that experimentally manipulated individuals (i.e. those provided with additional armor) were 1.6 times more likely to win a fight when compared to the control.

5. The implications of these results are twofold. First, our results experimentally support a fundamental assumption of most theoretical fighting models: that damage is a fighting cost that can influence contest outcomes. Second, these results highlight the importance of an individual's defensive capacity, and why defense should not be ignored. 
bioRxiv preprint doi: https://doi.org/10.1101/2020.11.02.365411; this version posted November 4, 2020. The copyright holder for this preprint (which was not certified by peer review) is the author/funder, who has granted bioRxiv a license to display the preprint in perpetuity. It is made available under aCC-BY 4.0 International license.

\section{KEY WORDS}

38 armor, cumulative-assessment model, damage, defense, intraspecific competition, mutual-

39 assessment model, sexually selected weapons, 


\section{1 | INTRODUCTION}

41 Fighting with conspecifics over access to limited resources (e.g. mates, food, or shelter) has been

42 documented in numerous animal species (Smith \& Price, 1973; West-Eberhard, 1983; Rico-

43 Guevara \& Hurme, 2019). For example, almost half of the sexually selected traits found in

44 animals are estimated to function in male-male competition (Wiens \& Tuschhoff, 2020). When

45 individuals of the same species compete, fighting often continues until a contestant withdraws.

46 Thus, theoretical studies have modeled the factors that determine an individual's willingness to

47 persist in a fight (Parker \& Rubenstein, 1981; Hammerstein \& Parker, 1982; Enquist \& Leimar,

48 1983; Mesterton-Gibbons et al., 1996; Payne \& Pagel, 1996; Payne, 1998). These theoretical

49 models can be categorized into one of three groups: pure self-assessment models, cumulative

50 assessment models, or mutual assessment models (Arnott \& Elwood, 2009). Both cumulative

51 and mutual assessment models assume that the costs contestants can inflict onto one another are

52 important factors in determining whether an individual should persist (Parker \& Rubenstein,

53 1981; Hammerstein \& Parker, 1982; Enquist \& Leimar, 1983; Payne, 1998). Thus, under these

54 models, injury should influence contest outcomes. There is correlative evidence to support this

55 assumption (e.g. Neat, Taylor, \& Huntingford, 1998; Moore et al., 2008). However, no study has

56 experimentally tested whether injury itself actually influences fighting success.

57 There are two main factors that determine injury potential during fights. The factor that

58 has received the most attention is an individual's offensive capacity. Traits that contribute to a

59 competitors offensive capacity include body size (Enquist et al., 1990; Leimar, Austad, \&

60 Enquist 1991), weaponry (Bean \& Cook, 2001), and skill (Briffa \& Lane, 2017). For example,

61 when Frontinella pyramitela spiders fight for a high-value resource, larger individuals are more

62 likely to win and injure their rival while doing so (Leimar et al., 1991). Similarly, Sycoscapter 
63 wasps with larger weapons inflict more damage (Bean \& Cook, 2001), and the individual with

64 the largest weapon is the most likely to win (Moore et al., 2008).

65 In addition to offensive capacity, another important factor that determines the potential

66 for injury is an individual's defensive capacity (Palaoro \& Briffa, 2017). One way that

67 individuals can increase their defensive capacity is through structures that reduce damage (Figure

68 1; Table 1). Examples include neck cornification in elephant seals (Le Boeuf, 1974), the head

69 dorsal convexity on hogbacked fig wasps (Murray, 1990), and the enlarged osteoderms of Cape

70 cliff lizards (Broeckhoven, De Kock \& Mouton, 2017). The latter example highlights that armor

71 traits classically associated with evading predation (i.e. osteoderms; Broeckhoven, Diedericks, \&

72 Mouton, 2015) may also serve a functional role in intraspecific fights (Broeckhoven et al., 2017).

73 Although numerous studies have identified these intraspecific, defensive structures (Figure 1;

74 Table 1), no study has investigated the degree to which they influence contest outcomes.

75 Here, we investigate whether inhibiting damage by enhancing an individual's armor

76 influences fighting behavior and success in the giant mesquite bug, Thasus neocalifornicus

77 (Insecta: Hemiptera: Coreidae). Males of several coreid species engage in intrasexual combat

78 over access to females and resources (Mitchell, 1980; Eberhard, 1998; Miller \& Emlen, 2010;

79 Procter, Moore, \& Miller, 2012; Tatarnic \& Spence, 2013). All coreid species that are known to

80 participate in these fights have hind legs with enlarged femurs and spines, including $T$.

81 neocalifornicus (Graham, Kaiser, \& Palaoro, 2020). Our observations indicate that when male $T$.

82 neocalifornicus engage in fights they place these spines onto the forewings of their rivals (Video

83 S1 and S2 in Supporting Information). This placement results in observable damage to the

84 forewing (Figure S1). Such damage appears to be costly, based on the melanization observed

85 around the wounds (Figure S1). This pattern of melanization in insects is indicative of an 
86 immune response, which can be metabolically expensive (Cerenius \& Soderhall, 2004; Ardia et

87 al., 2012). Moreover, wing damage in other insects has been shown to reduce flying ability

88 (Combes, Crall, \& Mukherjee, 2010; Mountcastle et al., 2016). Thus, the damage from these

89 fights may have consequences for an individual's ability to successfully flee from predators and

90 find mates.

91 Male Thasus neocalifornicus also appear to have a defense against forewing damage. Our

92 preliminary observations suggest that forewing thickness of male T. neocalifornicus is positively

93 allometric, and that male forewings are generally thicker than the forewings of similarly sized

94 females (Figure S2). These patterns indicate that forewing of males, and especially those of

95 larger males, could potentially be harder to puncture. Thus, additional wing thickness may serve

96 as a biological shield to prevent damage during intrasexual fights.

97 In this study, we experimentally enhanced the forewing thickness of Thasus

98 neocalifornicus. We predicted that experimentally enhancing this potential intrasexual shield

99 would provide males with a fighting advantage. We further predicted that these shields would

100 provide an advantage by enabling individuals to persist in fights longer, increasing the overall

101 length of the fight. This study provides the first experimental test of a fundamental assumption

102 included in most theoretical fighting models: that damage (and defense against that damage)

103 helps determine the contest winner.

1052 | MATERIALS AND METHODS

106

\section{1 | Specimens}

107 Adult male Thasus neocalifornicus used for this study were collected from the University of

108 Arizona Santa Rita Experimental Range (31.7921, -110.8813). All individuals were collected by 
109 hand on one of six days between the $15^{\text {th }}$ and $31^{\text {st }}$ of July, 2020. This timeframe was selected

110 because iNaturalist observations suggested that adult T. neocalifornicus could easily be found

111 during this month (as well as August and September). Before experimental trials, collected

112 individuals were housed in one of six mesh insect rearing containers $(305 \times 305 \times 607 \mathrm{~mm}$;

113 LxWxH; with up to 25 individuals per container). Individuals were provided with fresh cuttings

114 of velvet mesquite (Prosopis velutina) for food. Cuttings were replaced at least every 24 hours.

115 These large insect containers were kept inside at room temperature $\left(26^{\circ} \mathrm{C}\right)$, a temperature at

116 which males move slowly and do not seem to fight. This was done to prevent males from

117 engaging in behaviors in the holding containers that could have potentially influenced their

118 fighting behavior later on. Before experimentation, each individual was also marked with a

119 unique identifying number (using paint pens and permanent markers; Figure 2) and had their

120 pronotal width measured to the nearest micrometer using a Mitutoyo digital caliper. Pronotal

121 width is a widely used proxy for body size in this clade (Proctor et al., 2012; Emberts et al., 122 2020).

\section{2.2. | Experimental design}

125 Pairs of individuals were selected to engage in fights. Paired individuals were always collected

126 on the same day and had been in captivity for at least 4 hours (but not more than 36 hours).

127 Fighting pairs were size matched based on their pronotal widths (pronotal width difference of

$128 \leq 0.1 \mathrm{~mm})$. One individual per pair was then randomly assigned to be the focal individual using a

129 random number generator. Once the focal individual was identified it was randomly placed

130 (again, using a random number generator) into one of three treatments ( $n=50$ per treatment): (i)

131 comparative baseline, (ii) control, or (iii) experimental manipulation. One benefit of this 
132 randomized design is that in the unlikely case that fighting did occur in the holding containers,

133 the beneficiaries should be randomized among the treatments and focal males.

Focal individuals in the experimental manipulation treatment had a piece of additional

135 armor attached to their forewings. This was done to block or reduce damage from fights.

136 Specifically, each individual had a 12x16x1 mm piece of brown faux leather (100\% polyester)

137 glued onto their forewings (Figure 2C), using non-toxic Elmer's Glue-All mutli-purpose glue.

138 This faux leather was selected because it was light and because our previous observations

139 indicated that it could withstand attacks from Thasus neocalifornicus. The specific dimensions

140 were selected to ensure that a majority of the coria was covered: this is the thick and hardened

141 part of the forewings, where punctures from fights normally occur (Figure S1; Video S1 and S2).

142 Individuals in the control treatment had two $12 \times 8 \times 1 \mathrm{~mm}$ pieces of brown faux leather glued onto

143 their pronotum (Figure 2B). Our observations indicate that damage from fights does not occur at

144 this location. Thus, individuals in both treatments received the same amount of faux leather and

145 glue, but the location of the armor differed. Individuals in the comparative baseline treatment

146 were not provided with any additional armor (Figure 2A).

147 The additional weight added by the armor likely impeded the flying ability of individuals

148 in both the control and manipulation treatments. This should not be problematic for this

149 experiment because Thasus neocalifornicus males in the baseline treatment almost always left

150 fights by walking or running away (as opposed to flying away; Video S3 and S4). Moreover, our

151 previous observations of fighting behavior in other coreids suggest that walking or running away

152 is the most common form of retreating.

153 After undergoing their respective manipulations, focal individuals were placed into their

154 fighting arenas. A fighting arena consisted of a deli cup (top diameter: $118 \mathrm{~mm}$, bottom 
155 diameter: $85 \mathrm{~mm}$, height: $148 \mathrm{~mm}$ ) that had its walls lined with petroleum jelly (to keep

156 individuals from climbing out) and had a wooden dowel fixed in the middle (as a territory for

157 individuals to fight over; diameter: $4.7 \mathrm{~mm}$, height: $102 \mathrm{~mm}$; Video S1 and S2). This diameter

158 was selected because it was approximately equivalent to the diameter of branches that adult

159 males were collected on (e.g. Figure 1).

160 Thirty minutes after placing a focal individual in the arena, a rival individual (not

161 provided with armor) was placed into the arena as well. Fighting trials began once the rival male

162 was added and continued for the next two hours. Behavioral observations were made by two

163 individuals and each observer was allowed to watch up to 6 trials concurrently. Observers were

164 able to watch 6 trials concurrently for two reasons. First, fighting is fairly stereotypic in this

165 species and thus, it is easy to determine when a fight is about to begin (e.g. fights often began

166 once both individuals reached the top of the wooden dowel). Second, fights can occur for several

167 minutes, but the longest fights only lasted about 10 minutes (i.e. only a fraction of the 2 hour

168 observation period). All fighting trials occurred between 8am and 8pm, and occurred outside in

169 the shade. Air temperatures ranged from 34 to $41^{\circ} \mathrm{C}$ depending on the day and time. Time of

170 trials and air temperatures were recorded and analyzed as possible factors (see below).

171 Behavioral observations were noted during trials, including: (i) whether a

172 fighting/dominance interaction occurred, (ii) the duration of that interaction, (iii) whether a tibial

173 spine clearly struck the focal individual's wings (or the location of the wings, if covered by the

174 artificial shield), and (iv) which individual (if any) retreated following the interaction. Fighting

175 in other coreid species often includes displaying, charging, kicking, wrapping and grappling

176 (Emberts et al., 2018). Both observers were prepared to identify these behaviors in Thasus

177 neocalifornicus as well. However, most interactions involved only grappling, and only a few 
178 instances of charging were observed. Grappling is a stereotypic behavior in which males

179 ventrally align abdomen to abdomen and squeeze (or attempt to squeeze) one another (Video S1

180 and S2). Charging is a swift and directed movement toward the opponent. After each 2-hour

181 fighting trial, the number of retreats by each male was summed and the individual with the most

182 retreats was considered the subordinate individual (Proctor et al., 2012; Emberts et al., 2018). In

183 the case of ties (equal number of retreats), dominance was not assigned. For trials in which

184 attacks by rivals struck the artificial shield, we also confirmed that the attacks did not completely

185 puncture through the armor (i.e. that the armor prevented damage from occurring). All

186 individuals were used in only one trial, and were frozen immediately following their fighting

187 trial. Freezing the insects allowed us to use these individuals for future morphological

188 measurements.

\section{3 | Statistical analyses}

191 To test whether adding armor significantly influenced fighting behavior and success we

192 conducted a series of generalized linear models (GLMs). Our first model investigated whether

193 the treatment influenced the likelihood of fighting engagement between males. Engagement was

194 a categorical variable, and simply indicated whether a fight occurred during the two-hour trial.

195 This model initially included three continuous covariates: air temperature at the start of the trial

$196\left(34-41^{\circ} \mathrm{C}\right)$, the time of day that the fighting trial started $(8.75-18.75 \mathrm{~h})$, and the relative

197 difference in body size between the focal and rival male (-0.007-0.0085). Relative difference in

198 body size was calculated by subtracting the rival male's pronotal width from the focal male's

199 pronotal width and dividing this number by the average pronotal width of the two males. After

200 our initial model was constructed, we then removed insignificant covariates in a stepwise 
201 fashion, starting with the covariate that had the highest $p$-value. For these analyses, we used

$202 p>0.15$ to identify insignificant covariates (i.e. being more liberal about inclusion of potential

203 covariates than $p>0.05$, following Bursac et al., 2008). The model that was ultimately selected

204 included temperature, time, and treatment as explanatory variables. The main reason we

205 implemented this statistical approach was to ensure that none of the covariates (i.e. time,

206 temperature, or relative size difference) altered the influence of the treatment. We also confirmed

207 that excluding these covariates completely produced qualitatively similar results (see Results and

208 Table S1).

209 For our second and third analyses, we investigated whether treatment influenced the

210 number of fighting interactions (discrete: count data) that the focal and rival males engaged in.

211 We specifically conducted these analyses to determine whether armor influenced fighting

212 behavior of either the focal or rival male (e.g. Edmonds \& Briffa 2016). These analyses also

213 initially included time, temperature, and relative size difference as covariates. However, after

214 removing insignificant covariates from the model $(p>0.15)$ in a stepwise fashion, only treatment

215 and time remained as an explanatory variables (for both models).

216 Next, we investigated whether treatment influenced focal male dominance (categorical:

217 yes or no), where dominance was based on the individual having fewer retreats. This analysis

218 also initially included time, temperature, and relative size difference as covariates. However,

219 after removing insignificant covariates from the model $(p>0.15)$ in a stepwise fashion, only

220 treatment remained as an explanatory variable. Given a significant result, we then performed a

221 Tukey pair-wise comparison to determine which treatment was responsible for driving the

222 observed effect. 
For our fifth analysis, we investigated whether treatment influenced fighting duration

224 (continuous). Fighting duration was calculated for each focal male by taking the sum of all the

225 fighting interactions that the male engaged in during its two hour behavioral trial. For this

226 analysis we again included time, temperature, and relative size difference as covariates.

227 However, we also included focal male body size as an additional covariate, given that contest

228 duration is predicted to increase with body size under some fighting assessment models (Arnott

229 \& Elwood, 2009). We then performed stepwise removal of insignificant covariates from the

230 model $(p>0.15)$. Our fifth model ultimately included time and treatment as explanatory variables.

231 Visualization of diagnostic plots suggested that this analysis did not meet linear model

232 assumptions. Thus, fighting duration was $\log _{\mathrm{e}}$ transformed, and the diagnostic plots then

233 appeared to meet these assumptions.

234 We were also able to visually confirm that the focal male was struck on the wings (or the

235 location of the wings) by the rival's hindlimb(s) in 48 of the 150 fighting trials. If armor is

236 actually responsible for driving differences in fighting behavior and success, these 48 trials (i.e.

237 those that clearly require defense) should have a major influence on driving such a pattern.

238 Therefore, we conducted two additional GLMs in which we excluded fighting trials that did not

239 necessarily require defense (i.e. the other 102). These tests addressed whether treatment

240 influenced fighting duration and/or focal male dominance. The model for dominance initially

241 included time, temperature, and relative size difference as covariates, but after removing

242 insignificant covariates $(p>0.15)$, only time and treatment were included as explanatory

243 variables. Given a significant result, we again performed a Tukey pair-wise comparison to

244 determine which treatment drove the observed effect. The model for fighting duration initially

245 included time, temperature, relative size difference, and focal-male body size as covariates, but 
246 the final model only included treatment. Fighting duration was again $\log _{\mathrm{e}}$ transformed to meet

247 linear model assumptions.

248 All analyses were conducted in R version 3.6.0 (R Core Team, 2019).

\section{3 | RESULTS}

251 Out of 150 trials, 117 had at least one fighting interaction (78\%). However, we were only able to 252 determine the dominant male in 103 of the trials $(69 \%)$ because 14 of these trials ended in a tie 253 (i.e. equal number of retreats by both individuals). We found that treatment did not influence 254 whether an individual engaged in a fight $\left(\chi^{2}=0.804, \mathrm{df}=2, p=0.6692, n=150\right.$; Table S2).

255 Moreover, when fighting did occur, treatment did not influence the number of interactions that 256 an individual engaged in (focal male analysis: $\chi^{2}=1.160, \mathrm{df}=2, p=0.5598, n=117$; rival male

257 analysis: $\chi^{2}=0.513, \mathrm{df}=2, p=0.7737, n=117$; Tables S3 and S4). However, treatment did influence 258 fighting outcomes $\left(\chi^{2}=7.260, \mathrm{df}=2, p=0.0265, n=103\right)$. This latter effect was strongly driven by 259 our experimental manipulation (Figure 3A). Individuals with wing armor were 1.6 times more 260 likely to win fights (i.e. retreat less frequently) compared to those in the control treatment 261 (proportion of focal male dominance was 0.743 compared to $0.457 ; \mathrm{z}=2.396, p=0.0437, n=70$ ).

262 Moreover, wing-armored individuals were 1.5 times more likely to win fights compared to those 263 in the baseline treatment $(0.743$ compared to $0.485 ; \mathrm{z}=2.155, p=0.0790, n=68)$, although this 264 result was not significant.

The focal male was clearly struck on the wings (or the location of the wings) in 48 trials,

266 which were similarly distributed among treatments (baseline=13, control=18, manipulation=17).

267 If armor is actually responsible for driving the observed difference in fighting success, these 48

268 trials (i.e. those that required defense) should have a major role in driving the pattern. Thus, we 
excluded from our dataset fighting trials where it was unclear if defense was required and re-ran our main statistical analyses. We found that treatment significantly influenced fighting success

$271\left(\chi^{2}=13.775, \mathrm{df}=2, p=0.0010, n=48 ;\right.$ Table S5). This effect was again strongly driven by our

272 experimental manipulation (Figure 3B). Individuals with wing armor were 2.6 times more likely

273 to win fights compared to those in the control treatment $(0.824$ compared to $0.313 ; \mathrm{z}=3.002$,

$274 p=0.0075, n=35)$ and were 2.1 times more likely to win fights compared to those in the baseline 275 treatment $(0.824$ compared to $0.385 ; \mathrm{z}=2.754, p=0.0162, n=30)$.

276 The duration of the observed fights ranged from 2 to 621 seconds. Treatment did not

277 influence contest duration (Figure 4). This pattern was consistent regardless if we included all

278 fighting interactions $\left(\mathrm{F}_{2,112}=0.213, p=0.8087, n=116\right.$; Table S6) or just those that clearly required 279 defense $\left(\mathrm{F}_{2,44}=0.284, p=0.7539, n=47\right)$.

\section{4 | DISCUSSION}

282 We found that enhancing an individual's defensive capacity increases their fighting success.

283 Male Thasus neocalifornicus that were experimentally prevented from being injured (by their

284 rivals) during intrasexual contests were 1.6 times more likely to win fights compared to the

285 control. Thus, our results demonstrate that damage (and defense) have important roles in

286 determining contest outcomes. Most theoretical fighting models (e.g. cumulative and mutual

287 assessment models; Arnott \& Elwood, 2009) have assumed this to be the case (Parker \&

288 Rubenstein, 1981; Hammerstein \& Parker, 1982; Enquist \& Leimar, 1983; Payne, 1998).

289 However, the validity of this assumption has not been experimentally demonstrated before. 
shield (i.e. wing thickness) increased fighting success (which it did; Figure 3). Second, it allowed us to prevent damage without manipulating the weapons. Previous weapon removal studies have

294 demonstrated that weapons have an important role in determining contest outcomes (e.g.

295 Espmark, 1964; Rilich, Schildberger, \& Stevenson, 2007; Yasuda, Suzuki, \& Wada, 2011;

296 Emberts et al., 2018). However, these studies cannot (nor do they claim to) demonstrate that

297 damage influences fighting success because weapons do not solely inflict damage. For example,

298 some weapons also serve as signals (McCullough, Miller, \& Emlen, 2016), while others can be

299 used to exclude individuals from a resource without causing injury (Emlen, 2008). With that

300 said, weapon removal studies can also prevent damage from occurring. Thus, these studies

301 remain crucial, and it is still useful to compare these studies with ours.

302 Experimentally providing one contestant with armor did not increase fighting duration, in

303 contrast to our prediction. There are several factors that could have influenced our ability to

304 detect this effect here. For this study, total fighting duration was based on the sum of all fighting

305 interactions, and fighting interactions generally ended when one of the individuals fled. In those

306 cases, it was the individual that fled that determined the length of that specific fighting

307 interaction. Since a majority of unarmored individuals lost (i.e. retreated more often), it was

308 mostly unarmored individuals (as opposed to armored individuals) contributing to the fighting

309 duration. Thus, armor likely only had a small effect on the overall duration of the contest.

310 Another factor to consider is that the length of fights were quite variable within treatments. Thus,

311 even though armored individuals spent slightly more time fighting than focal individuals in the

312 other treatments (4s longer than the control and 24s longer than the comparative baseline; Figure

313 4), a much larger sample size would be needed to detect such a small effect. Our finding that

314 armor does not substantially increase contest duration is consistent with the results of weapon 
315 removal studies in which only one contestant has their weapons removed (Rilich et al., 2007;

316 Emberts et al., 2018). However, when both contestants have their weapons removed, fighting

317 duration has been shown to increase (Rillich et al., 2007). Thus, future studies that aim to

318 determine whether damage per se influences the length of fights should compare the fighting

319 duration of contests where both individuals are armored to those in which both individuals are

320 unarmored.

321 All theoretical models of fighting assume that contestants gather information regarding

322 the costs and benefits of persisting. However, these models vary in the exact type of information

323 that a contestant is thought to gather (Arnott \& Elwood, 2009). Both cumulative and mutual

324 assessment models assume that the costs individuals can inflict onto one another (e.g. damage)

325 are important factors in determining whether each individual should persist (Parker \&

326 Rubenstein, 1981; Hammerstein \& Parker, 1982; Enquist \& Leimar, 1983; Payne, 1998). Here,

327 we provide experimental support for this assumption. However, damage can also be self-inflicted

328 (Lane \& Briffa, 2017). For example, the antlers of deer can break during high intensity fights

329 (Alvarez, 1993; Lane \& Briffa, 2017). In such cases, damage could also influence how long an

330 individual is willing to persist in a fight even when models assume that fighting costs are only

331 self-imposed, as in the 'war of attrition without assessment' model (Mesterton-Gibbons, Marden,

332 \& Dugatkin, 1996). This is considered a pure-self assessment model (Arnott \& Elwood, 2009).

333 Thus, the cost of damage (in its broadest sense) may influence contest outcomes under self,

334 cumulative, and mutual assessment models.

335 We focused here on defensive structures that reduce damage (e.g. Table 1, Figure 1), but

336 there are other ways that defensive structures can limit the effectiveness of a rival's weapon. For

337 example, a defensive structure can make it harder for an individual to be removed from a 
resource (e.g. Benowitz, Brodie III, \& Formica, 2012) or they may make it more difficult for an individual to be reached during the fight (e.g. Eberhard, Garcia-C, \& Lobo, 2000). A particularly compelling example of removal resistance involves the grip strength of forked fungus beetles,

341 Bolitotherus cornutus (Benowitz et al., 2012). Males of this species mate guard by standing on

342 top of the female (Liles, 1956). Thus, rival males must use their clypeal horn to physically pry 343 guarding males off of the female before attempting to mate (Benowitz et al., 2012). Therefore,

344 grip strength and leg size are important factors that prevent the effectiveness of a rival's weapon

345 in this system. Overall, intrasexual, defensive structures may take on many forms and future 346 work should continue to quantify their diversity and prevalence throughout Animalia.

In summary, we investigated whether enhancing an individual's armor influenced

348 fighting behavior and success. We found that experimentally manipulated individuals (i.e. those

349 provided with armor) gained a $60 \%$ increase in fighting success when compared to the control

350 individuals. This result demonstrates that damage can have an important role in determining

351 contest outcomes. Thus, this result experimentally supports a fundamental assumption of many

352 theoretical fighting models. Although damage has long been considered an important component

353 of contest outcomes (e.g. Smith \& Price, 1973), damage-reducing structures (i.e. biological

354 shields) have largely been overlooked. These defensive structures are taxonomically widespread

355 (Table 1), may show considerable variation within species (Figure S1), and can significantly

356 influence contest outcomes (Figure 3). Thus, our results highlight the need to further investigate

357 the evolutionary ecology of these defensive structures. 


\section{ACKNOWLEDGEMENTS}

362 We thank Cody Howard for his help with data collection and Zack Graham for his input on how

363 to design the fighting arenas. We also thank the anonymous reviewers for providing feedback on

364 an earlier version of the manuscript. This work was supported by NSF grant DBI-1907051

365 awarded to ZE. We have no conflicts of interest to declare.

\section{AUTHOR CONTRIBUTIONS}

368 ZE conceived the experiment, collected and analyzed the data, and led the writing of the

369 manuscript. JJW critically revised the manuscript and gave final approval for publication.

\section{REFERENCES}

372 Alvarez, F. (1993). Risks of fighting in relation to age and territory holding in fallow deer. Canadian Journal of Zoology, 71, 376-383.

374 Ardia, D. R., Gantz, J. E., \& Strebel, S. (2012). Costs of immunity in insects: an induced immune response increases metabolic rate and decreases antimicrobial activity. Functional

377 Bean, D., \& Cook, J. M. (2001). Male mating tactics and lethal combat in the nonpollinating fig wasp Sycoscapter australis. Animal Behaviour, 62, 535-542.

379 Benowitz, K. M., Brodie III, E. D., \& Formica, V. A. (2012). Morphological correlates of a combat performance trait in the forked fungus beetle, Bolitotherus cornutus. PLoS One, 7 , e42738.

Briffa, M., \& Lane, S. M. (2017). The role of skill in animal contests: a neglected component of fighting ability. Proceedings of the Royal Society B: Biological Sciences, 284, 20171596. 
384 Broeckhoven, C., de Kock, C., \& Mouton, P. L. F. N. (2017). Sexual dimorphism in osteoderm expression and the role of male intrasexual aggression. Biological Journal of the Linnean Society, 122, 329-339.

Broeckhoven, C., De Kock, C., \& Hui, C. (2018). Sexual dimorphism in the dermal armour of cordyline lizards (Squamata: Cordylinae). Biological Journal of the Linnean Society, 125,

Broeckhoven, C., Diedericks, G., \& Mouton, P. L. F. N. (2015). What doesn't kill you might make you stronger: functional basis for variation in body armour. Journal of Animal

Bursac, Z., Gauss, C. H., Williams, D. K., \& Hosmer, D. W. (2008). Purposeful selection of Ecology, 84, 1213-1221.

Cerenius, L., \& Söderhäll, K. (2004). The prophenoloxidase-activating system in

Combes, S. A., Crall, J. D., \& Mukherjee, S. (2010). Dynamics of animal movement in an ecological context: dragonfly wing damage reduces flight performance and predation success. Biology Letters, 6, 426-429.

Eberhard, W. G. (1998). Sexual behavior of Acanthocephala declivis guatemalana (Hemiptera:

403 Eberhard, W. G., Garcia-C, M., \& Lobo, J. (2000). Size-specific defensive structures in a horned weevil confirm a classic battle plan: avoid fights with larger opponents. Proceedings of the Royal Society of London. Series B: Biological Sciences, 267, 1129-1134.

406 Edmonds, E., \& Briffa, M. (2016). Weak rappers rock more: hermit crabs assess their own 
agonistic behaviour. Biology Letters, 12, 20150884.

Emberts, Z., St. Mary, C. M., Herrington, T. J., \& Miller, C. W. (2018). Males missing their competitive environment. Behavioral Ecology and Sociobiology, 72, 81.

411 Emberts, Z., St. Mary, C.M., Howard, C.C., Forthman, M., Bateman, P.W., Somjee, U., Hwang,

414 Emlen, D. J. (2008). The evolution of animal weapons. Annual Review of Ecology, Evolution, and Systematics, 39, 387-413.

English, L. T. (2018a). Evolution of functional morphology of osteoderms across

English, L. T. (2018b). Variation in crocodilian dorsal scute organization and geometry with a discussion of possible functional implications. Journal of Morphology, 279, 154-162.

Enquist, M., Leimar, O., Ljungberg, T., Mallner, Y., \& Segerdahl, N. (1990). A test of the sequential assessment game: fighting in the cichlid fish Nannacara anomala. Animal

Enquist, M., \& Leimar, O. (1983). Evolution of fighting behaviour: decision rules and assessment of relative strength. Journal of Theoretical Biology, 102, 387-410. domestic reindeer (Rangifer tarandus L.). Animal Behaviour, 12, 420-426.

427 Geist, V. (1967). On fighting injuries and dermal shields of mountain goats. The Journal of Wildlife Management, 31, 192-194.

429 Graham, Z. A., Kaiser, N., \& Palaoro, A. V. (2020). Performance, but not size, of hindleg 
weaponry is sexually dimorphic in the giant mesquite bug (Thasus neocalifornicus). bioRxiv. doi: 10.1101/2020.08.03.234385.

Hammerstein, P., \& Parker, G. A. (1982). The asymmetric war of attrition. Journal of Theoretical Biology, 96, 647-682.

434 Jarman, P. J. (1972). The development of a dermal shield in impala. Journal of Zoology, 166, $435 \quad 349-356$.

436 Jarman, P. J. (1989). On being thick-skinned: dermal shields in large mammalian 437 herbivores. Biological Journal of the Linnean Society, 36, 169-191.

438 Lane, S. M., \& Briffa, M. (2017). The price of attack: rethinking damage costs in animal 439 contests. Animal Behaviour, 126, 23-29.

440 Le Boeuf, B. J. (1974). Male-male competition and reproductive success in elephant $441 \quad$ seals. American Zoologist, 14, 163-176.

442 Leimar, O., Austad, S., \& Enquist, M. (1991). A test of the sequential assessment game: fighting 443 in the bowl and doily spider Frontinella pyramitela. Evolution, 45, 862-874.

444 McCullough, E. L., Miller, C. W., \& Emlen, D. J. (2016). Why sexually selected weapons are 445 not ornaments. Trends in Ecology \& Evolution, 31, 742-751.

446 Mountcastle, A. M., Alexander, T. M., Switzer, C. M., \& Combes, S. A. (2016). Wing wear 447 reduces bumblebee flight performance in a dynamic obstacle course. Biology Letters, 12, $448 \quad 20160294$.

449 Mesterton-Gibbons, M., Marden, J. H., \& Dugatkin, L. A. (1996). On wars of attrition without $450 \quad$ assessment. Journal of Theoretical Biology, 181, 65-83.

451 Miller, C. W., \& Emlen, D. J. (2010). Across-and within-population differences in the size and 452 scaling relationship of a sexually selected trait in Leptoscelis tricolor (Hemiptera: 
Coreidae). Annals of the Entomological Society of America, 103, 209-215.

454 Mitchell, P. L. (1980). Combat and territorial defense of Acanthocephala femorata (Hemiptera:

455 Coreidae). Annals of the Entomological Society of America, 73, 404-408.

456 Moore, J. C., Obbard, D. J., Reuter, C., West, S. A., \& Cook, J. M. (2008). Fighting strategies in 457 two species of fig wasp. Animal Behaviour, 76, 315-322.

458 Murray, M. G. (1990). Comparative morphology and mate competition of flightless male fig wasps. Animal Behaviour, 39, 434-443.

460 Neat, F. C., Taylor, A. C., \& Huntingford, F. A. (1998). Proximate costs of fighting in male cichlid fish: the role of injuries and energy metabolism. Animal Behaviour, 55, 875-882.

Palaoro, A. V., \& Briffa, M. (2017). Weaponry and defenses in fighting animals: how allometry can alter predictions from contest theory. Behavioral Ecology, 28, 328-336.

Parker, G. A., \& Rubenstein, D. I. (1981). Role assessment, reserve strategy, and acquisition of information in asymmetric animal conflicts. Animal Behaviour, 29, 221-240.

Payne, R. J., \& Pagel, M. (1996). Escalation and time costs in displays of endurance. Journal of Theoretical Biology, 183, 185-193.

Payne, R. J. (1998). Gradually escalating fights and displays: the cumulative assessment model. Animal Behaviour, 56, 651-662.

470 Procter, D. S., Moore, A. J., \& Miller, C. W. (2012). The form of sexual selection arising from male-male competition depends on the presence of females in the social environment. Journal of Evolutionary Biology, 25, 803-812.

473 R Core Team. (2019). R: A language and environment for statistical computing. Vienna, Austria.

474 Rico-Guevara, A., \& Hurme, K. J. (2019). Intrasexually selected weapons. Biological

$475 \quad$ Reviews, 94, 60-101. 
Rillich, J., Schildberger, K., \& Stevenson, P. A. (2007). Assessment strategy of fighting crickets revealed by manipulating information exchange. Animal Behaviour, 74, 823-836.

478 Sathar, F., Ludo Badlangana, N., \& Manger, P. R. (2010). Variations in the thickness and composition of the skin of the giraffe. The Anatomical Record: Advances in Integrative

Shadwick, R. E., Russell, A. P., \& Lauff, R. F. (1992). The structure and mechanical design of rhinoceros dermal armour. Philosophical Transactions of the Royal Society of London. Series B: Biological Sciences, 337, 419-428.

Smith, J. M., \& Price, G. R. (1973). The logic of animal conflict. Nature, 246, 15-18.

Tatarnic, N. J., \& Spence, J. R. (2013). Courtship and mating in the crusader bug, Mictis profana (Fabricius). Australian Journal of Entomology, 52, 151-155.

Taylor, J. R. A., Scott, N. I., \& Rouse, G. W. (2019). Evolution of mantis shrimp telson armour

Taylor, J. R. A., \& Patek, S. N. (2010). Ritualized fighting and biological armor: the impact mechanics of the mantis shrimp's telson. Journal of Experimental Biology, 213, 3496-3504.

491 Vickaryous, M. K., Meldrum, G., \& Russell, A. P. (2015). Armored geckos: A histological investigation of osteoderm development in Tarentola (Phyllodactylidae) and Gekko (Gekkonidae) with comments on their regeneration and inferred function. Journal of 
499 Yaraghi, N. A., Trikanad, A. A., Restrepo, D., Huang, W., Herrera, S., Rivera, J., Zhernenkov,

$500 \quad$ M., Parkinson, D. Y., Caldwell, R. L., Zavattieri, P. D., \& Kisailus, D. (2019). The

501 stomatopod telson: convergent evolution in the development of a biological

$502 \quad$ shield. Advanced Functional Materials, 29, 1902238.

503 Yasuda, C., Suzuki, Y., \& Wada, S. (2011). Function of the major cheliped in male-male

504 competition in the hermit crab Pagurus nigrofascia. Marine Biology, 158, 2327-2334. 


\section{SUPPORTING INFORMATION}

507 Figure S1. Examples of forewing damage found in wild caught Thasus neocalifornicus males

508 Figure S2. Forewing thickness of Thasus neocalifornicus is sexually dimorphic and positively

509 allometric.

510 Table S1. Completely excluding covariates from our seven generalized linear models produces

511 qualitatively similar results.

512 Table S2. The role of treatment, time of day, and temperature on fighting engagement.

513 Table S3. The role of treatment and time of day on the number of fighting interactions that focal

514 males engaged in.

515 Table S4. The role of treatment and time of day on the number of fighting interactions that rival

516 males engaged in.

517 Table S5. The role of treatment and time of day on focal male dominance in fights that require

518 defense.

519 Table S6. The role of treatment and time of day on fighting duration (which was $\log _{\mathrm{e}}$

520 transformed).

521 Video S1. Two Thasus neocalifornicus males grappling.

522 Video S2. Two Thasus neocalifornicus males grappling, at half speed.

523 Video S3. A Thasus neocalifornicus male retreating a fight by running away.

524 Video S4. A Thasus neocalifornicus male retreating a fight by running away, at half speed. 
526 TABLE 1 Examples of non-weapon structures that are thought to reduce damage from accruing

527 during intraspecific fights. This list was initially compiled by reading Jarman (1989) and

528 conducting a forward citation search. We then added additional examples of defensive structures

529 that we knew were referenced in the literature.

\begin{tabular}{|c|c|c|c|}
\hline Group & $\begin{array}{l}\text { Defensive } \\
\text { structure }\end{array}$ & Species & Reference \\
\hline \multicolumn{4}{|l|}{ Vertebrates } \\
\hline Crocodilians & $\begin{array}{l}\text { Scutes and } \\
\text { osteoderms }\end{array}$ & $\begin{array}{l}\text { Alligator mississippiensis, Caiman } \\
\text { crocodilus, Ca. yacare, Crocodylus } \\
\text { niloticus, Cr. porosus, Paleosuchus } \\
\text { trigonatus }\end{array}$ & $\begin{array}{l}\text { English } \\
(2018 a, b)\end{array}$ \\
\hline \multicolumn{4}{|l|}{ Mammals } \\
\hline $\begin{array}{l}\text { Antilocapridae } \\
\text { (pronghorns) }\end{array}$ & Dermal thickening & Antilocapra americana & Jarman (1989) \\
\hline $\begin{array}{l}\text { Bovidae } \\
\text { (Bovids) }\end{array}$ & Dermal thickening & $\begin{array}{l}\text { Aepyceros melampus, Connochaetes } \\
\text { taurinus, Damaliscus korrigum, } \\
\text { Gazella granti, Oreamnos } \\
\text { americanus, Ovis dalli, O. canadensis, } \\
\text { Taurotragus oryx }\end{array}$ & $\begin{array}{l}\text { Geist }(1967, \\
\text { 1971); Jarman } \\
(1972,1989)\end{array}$ \\
\hline $\begin{array}{l}\text { Camelidae } \\
\text { (camels) }\end{array}$ & Dermal thickening & Camelus dromedarius & Jarman (1989) \\
\hline $\begin{array}{l}\text { Giraffidae } \\
\text { (giraffes) }\end{array}$ & Dermal thickening & Giraffa camelopardalis & $\begin{array}{l}\text { Sathar et al. } \\
(2010)\end{array}$ \\
\hline $\begin{array}{l}\text { Hippopotamidae } \\
\text { (hippopotamuses) }\end{array}$ & Dermal thickening & Hippopotamus amphibius & Jarman (1989) \\
\hline $\begin{array}{l}\text { Leporidae } \\
\text { (rabbits \& hares) }\end{array}$ & Dermal thickening & Oryctolagus cuniculus & Jarman (1989) \\
\hline $\begin{array}{l}\text { Marsupiala } \\
\text { (marsupials) }\end{array}$ & Dermal thickening & $\begin{array}{l}\text { Aepyprymnus rufescens, } \text { Macropus } \\
\text { fuliginosus, } \text { M. giganteus, } M . \\
\text { robustus, } \text { M. rufus, Thylogale thetis, } \\
\text { Vombatus ursinus }\end{array}$ & Jarman (1989) \\
\hline $\begin{array}{l}\text { Pinnipedia } \\
\text { (pinnipeds) }\end{array}$ & Neck cornification & Mirounga augustirostris & $\begin{array}{l}\text { Le Boeuf } \\
(1974)\end{array}$ \\
\hline $\begin{array}{l}\text { Rhinocerotidae } \\
\text { (rhinoceros) }\end{array}$ & $\begin{array}{l}\text { Dermal thickening, } \\
\text { increased strength } \\
\text { and stiffness of skin }\end{array}$ & Ceratotherium simum, & $\begin{array}{l}\text { Shadwick et al. } \\
\text { (1992) }\end{array}$ \\
\hline $\begin{array}{l}\text { Suidae } \\
\text { (pigs) }\end{array}$ & Dermal thickening & Sus scrofa & Jarman (1989) \\
\hline $\begin{array}{l}\text { Tragulidae } \\
\text { (mouse-deer) }\end{array}$ & Dermal thickening & Hyemoschus aquaticus & Jarman (1989) \\
\hline
\end{tabular}


Squamata (lizards) Osteoderms

\section{Arthropods}

Agaonidae

(fig wasps)

Coreidae

(leaf-footed bugs)

Stomatopoda

(mantis shrimps) increased thorax

Cuticular thickening Telson
Hemicordylus capensis, Tarentola americana, T. annularis, T. chazaliae, T. crombei, T. mauritanica, Gekko gecko, Hemicordylus capensis, Smaug depressus

Dorsal convexity, sclerotization of
Eujacobsonia genalis, Lipothymus sundaicus, Otitesellinae sp.

Thasus neocalifornicus

Gonodactylaceus falcatus, $G$. espinosus, G. chiragra, G. smithii, Haptosquilla glyptocercus, $H$. trispinosa, Neogonodactylus bredini, $N$. festae, N. oerstedii, N. wennerae, Odontodactylus latirostris, $O$. scyllarus,
Vickaryous et

al. (2015)

Broeckhoven et

al. $(2017,2018)$

Murray (1990)

Figure S2

Taylor \& Patek (2010); Yaraghi et al. (2019); Taylor et al. (2019) 


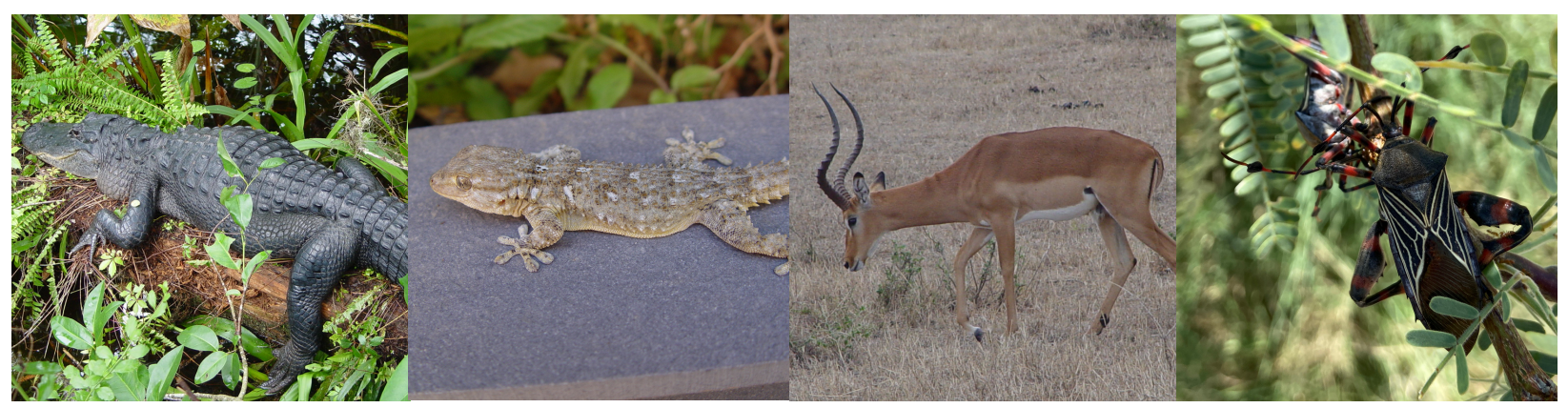

533 FIGURE 1 Photographs of animals thought to have defensive structures associated with

534 intraspecific combat. From left to right: Alligator mississippiensis (dorsal osteoderms and

535 scutes), Tarentola mauritanica (osteoderms), Aepyceros melampus (dermal thickening around

536 the head, neck, and shoulders), and Thasus neocalifornicus (cuticular thickening of the

537 forewings). See Table 1 for references and additional examples. Photo credits: first three on the

538 left: John J. Wiens; right: Zachary Emberts. 


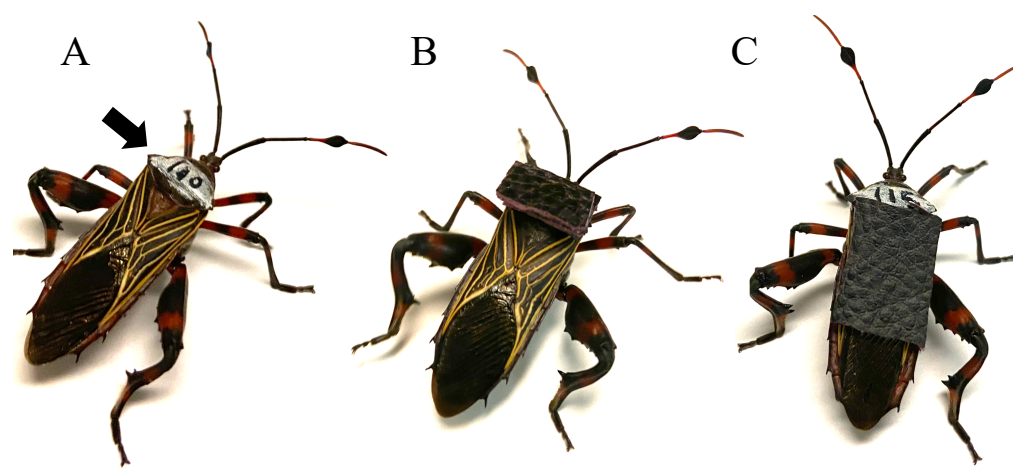

543 FIGURE 2 Photos of individuals of the giant mesquite bug (Thasus neocalifornicus) illustrating

544 different treatments in this study. Individuals in the comparative baseline treatment (A) were not

545 provided with armor. Individuals in the control treatments (B) were provided with two

$54612 \times 8 \times 1 \mathrm{~mm}$ piece of brown faux leather stacked and glued onto their pronotum. This provided

547 the same weight as the experimental treatment, but was not in a location that is damaged in

548 combat. Finally, individuals in the experimental manipulation treatment (C) were provided with

549 a 12x16x1mm piece of brown faux leather glued onto their forewings. This was intended to

550 protect their forewings from damage during intraspecific male-male combat. The forewings are

551 the site where punctures occur during intraspecific combat (Fig. S1). Arrow in A indicates where

552 individuals were uniquely identified by using paint pens and permanent markers. 

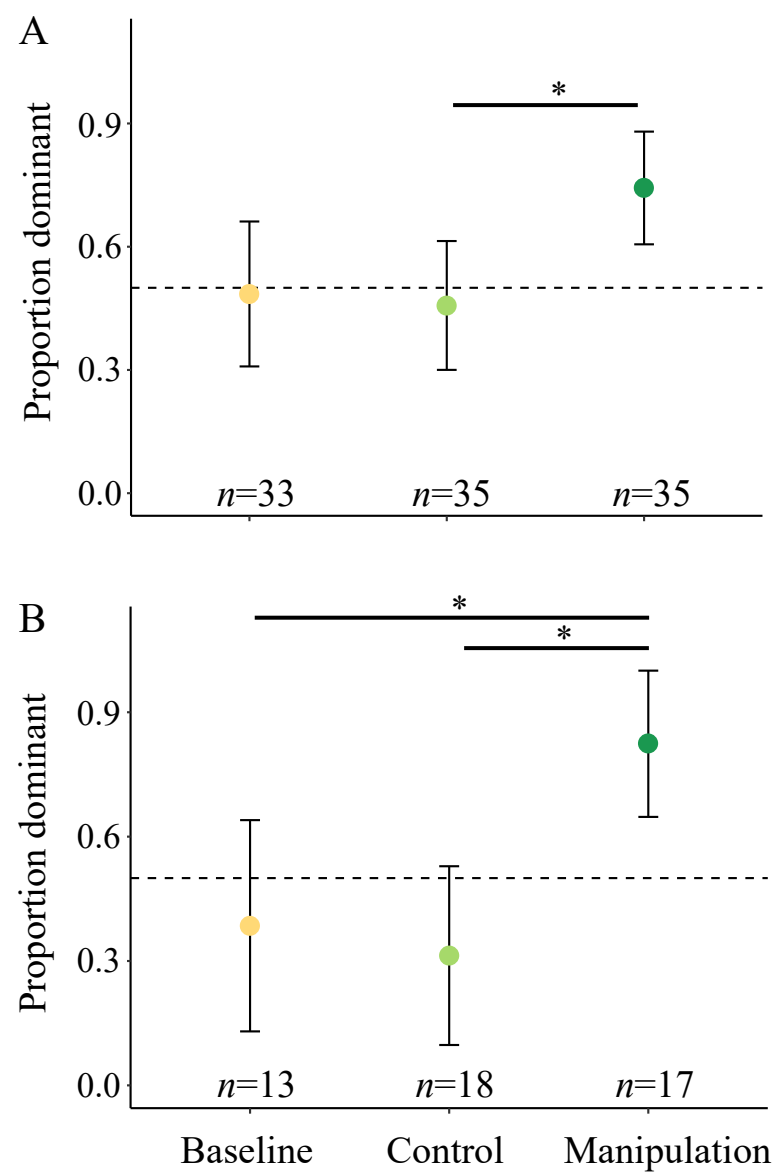

555 FIGURE 3 Defensive structures influence contest outcomes. Experimentally manipulated males

556 (with armor added to protect their wings) were more likely to win fights (i.e. be dominant) than

557 males in the control treatment and males in the baseline treatment. This pattern was consistent

558 regardless if all fighting interactions were included in the analysis (A) or just those interactions

559 in which the focal male was clearly struck on the wings (or the location of the wings if the wings

560 were armored), and that therefore specifically required defense (B). The dashed line at 0.5

561 indicates the expected proportion of focal male dominance under random chance and error bars

562 depict 95\% confidence intervals. Asterisks indicate statistical significance between treatments. 

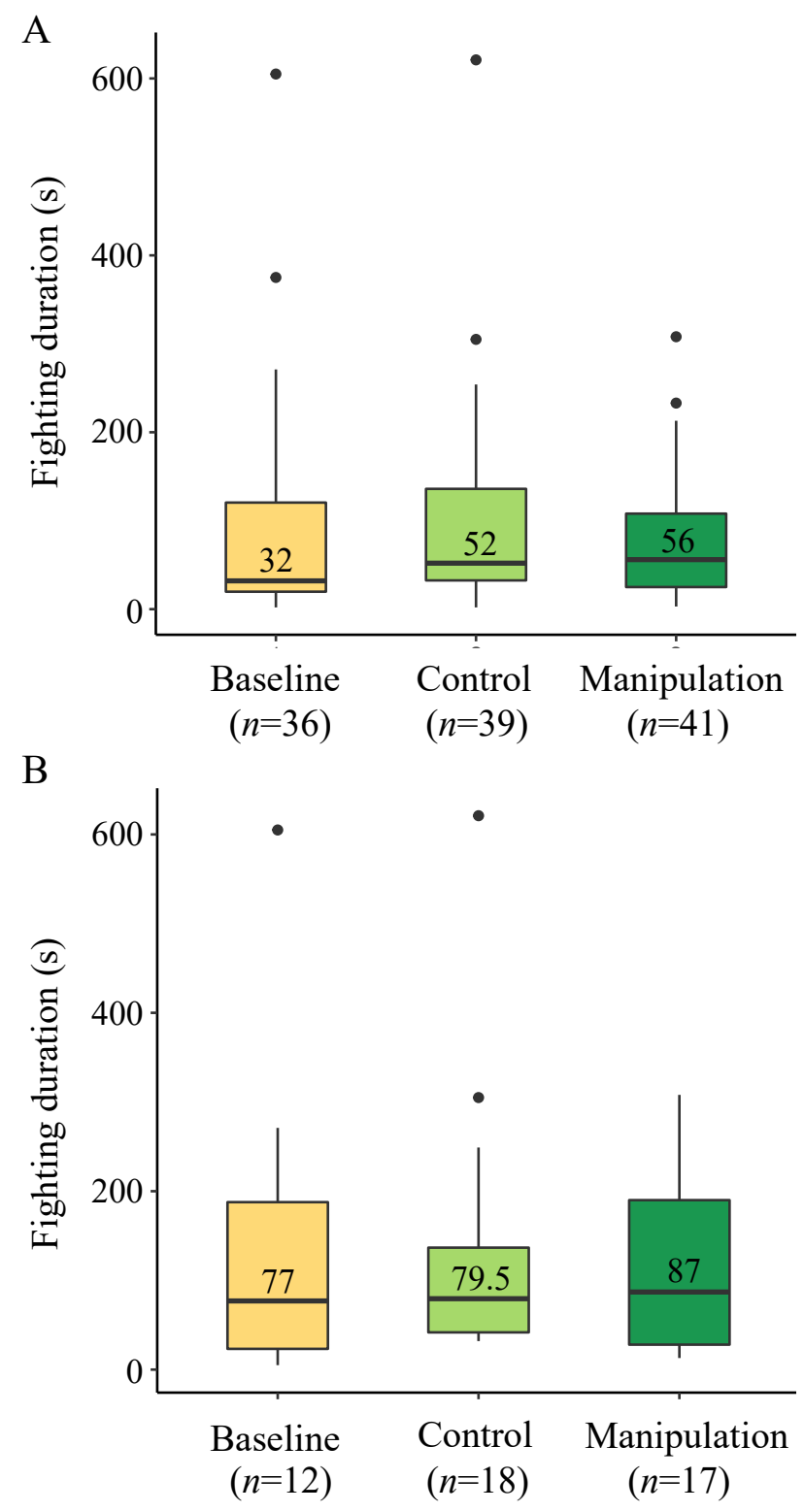

565 FIGURE 4 Fighting duration was unaffected by treatment. This result was consistent regardless

566 if we included all fighting interactions (A) or just those that clearly required defense (B). The

567 boxes indicate a treatment's interquartile range, while the numbers in boxes indicate the median

568 fighting duration (in seconds) for each treatment. Data points indicate outliers, and whiskers

569 indicate a treatment's range when excluding those outliers. These outliers were included in the

$570 \quad$ statistical analyses. 